Check for updates

Cite this: Mater. Adv., 2021, 2, 6049

Received 23rd June 2021, Accepted 11th August 2021

DOI: $10.1039 / \mathrm{d} 1 \mathrm{ma} 00547 \mathrm{~b}$

rsc.li/materials-advances

\title{
Sustainable glycerol carbonate electrolytes for Li-ion supercapacitors: performance evaluation of butyl, benzyl, and ethyl glycerol carbonates $\dagger$
}

\author{
Maryam Salari, (D) a Jennifer Chapman Varela, (D) ${ }^{a}$ Heng Zhang $^{a}$ and \\ Mark W. Grinstaff (iD *ab
}

\begin{abstract}
Substitution of flammable, toxic solvents in electrolytes with alternative green options is of significant commercial and environmental interest. Here, we report the synthesis and physicochemical properties of glycerol carbonate (GlyC) based solvents as electrochemically stable electrolytes for lithium ion supercapacitors. Glycerol carbonates with pendent butyl, benzyl, and ethyl side chains are all thermally stable and exhibit compositional dependent properties. Of the three glycerol-based electrolytes, the butyl and ethyl GlyC analogs exhibit the highest conductivity and discharge capacitance at room and elevated temperatures. The new electrolytes allow for safe operation of a Li-ion supercapacitor at room temperature and $100{ }^{\circ} \mathrm{C}$, with specific capacitances between 115 and $162 \mathrm{~F} \mathrm{~g}^{-1}$, and good electrochemical performance at $100^{\circ} \mathrm{C}$.
\end{abstract}

\section{Introduction}

Electrical energy storage (EES) systems are critical to a sustainable energy solution and include devices such as lithium ion batteries (LIBs) and supercapacitors (ECs). Due to the demand for both energy and power, a new EES device that combines the charging mechanisms of LIBs and ECs is emerging: lithium-ion supercapacitors (LICs). ${ }^{1,2}$ An essential component of sustainable energy is expanding the use of EES devices beyond $35{ }^{\circ} \mathrm{C}$, as such, significant research efforts are dedicated to investigating key device components, such as the electrodes, separator, and electrolyte, to identify thermally stable materials for new high temperature stable EES devices. ${ }^{3-8}$ Our interest is in thermally stable electrolytes and, specifically, electrolytes that are also ecologically sustainable.

In commercial devices, an organic solvent, such as acetonitrile (ACN), containing a lithium salt is the most common electrolyte due to their rapid ion transport and high conductivity (tens of $\mathrm{mS} \mathrm{cm}^{-1}$ ). ${ }^{1,9-11}$ However, the major limitations of these electrolytes are their high volatility, flammability (due to the very low flash point of $\mathrm{ACN}\left(\sim 5{ }^{\circ} \mathrm{C}\right)$ ), and toxicity. These limitations carry significant health and

\footnotetext{
${ }^{a}$ Department of Chemistry, Boston University, 590 Commonwealth Avenue, Boston, MA 02215, USA. E-mail: mgrin@bu.edu

${ }^{b}$ Department of Biomedical Engineering, Boston University, 590 Commonwealth Ave, Boston, MA 02215, USA

$\dagger$ Electronic supplementary information (ESI) available. See DOI: 10.1039/ d1ma00547b
}

environmental risks and render them impractical for high temperature applications. To address the limitations of ACN, cyclic organic solvents such as propylene carbonate, linear ethylene carbonate, or dimethyl carbonate solvents, are utilized: but poor ion ordering and solvent degradation at elevated temperatures are substantial obstacles. ${ }^{12,13}$

As an alternative to these solvents, we are designing, synthesizing, and evaluating sustainable and environmentally friendly organic carbonate electrolytes based on glycerol. Fig. 1 shows the molecular structures of the glycerol carbonates with an ethyl, benzyl, or butyl side chain (i.e., 3-ethoxy-1,2-propylene carbonate, 3-benzyloxy-1,2-propylene carbonate, and 3-butoxy1,2-propylene carbonate) compared to conventional cyclic carbonates ethylene carbonate (EC) and dimethyl carbonate (DMC). The building blocks and the degradation products for two of the glycerol carbonates are glycerol, $\mathrm{CO}_{2}$, and ethanol or

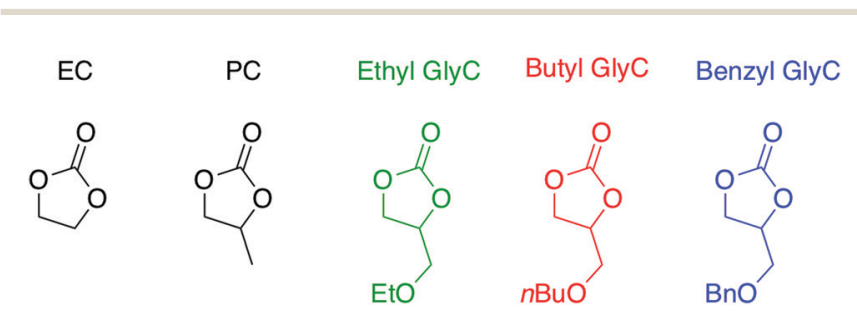

Fig. 1 Chemical structures of carbonate solvents ethylene carbonate (EC), propylene carbonate (PC), compared to Ethyl (C2; 3-ethoxy-1,2propylene carbonate), Butyl (C4; 3-butoxy-1,2-propylene carbonate), and Benzyl (C7; 3-benzyloxy-1,2-propylene carbonate) glycerol carbonates (GlyCs). 
butanol, which are natural, benign, and recyclable compounds. Moreover, the building blocks can be produced commercially from non-petroleum sources, making the glycerol compounds, from synthesis to degradation, environmentally sustainable. The third glycerol carbonate electrolyte, included for comparison, contains a benzyl group and is not as sustainable due to the benzyl group. Herein, we report the synthesis and characterization of three glycerol-based carbonate solvents possessing different pendant chains: ethyl, benzyl, and butyl (Fig. 1). Additionally, we describe the influence of the pendant chain composition on thermal stability, viscosity, and conductivity as a function of temperature. The performance of LICs equipped with the three glycerol-based carbonates and 1.0 M LiTFSI electrolyte is also reported at $20{ }^{\circ} \mathrm{C}$ and $100{ }^{\circ} \mathrm{C}$.

\section{Experimental procedures}

\section{Synthesis of glycerol carbonates}

Benzyl glycidyl ether $(5.0 \mathrm{~mL}, 32.9 \mathrm{mmol})$ was added into a predried $50 \mathrm{~mL}$ round bottomed flask. Triphenylphosphine (1.29 g, $4.93 \mathrm{mmol}, 0.15$ eq.) and $\operatorname{InBr}_{3}(1.75 \mathrm{~g}, 4.93 \mathrm{mmol}, 0.15$ eq.) were added, and the mixture was stirred until all the $\mathrm{InBr}_{3}$ dissolved, and the liquid became homogenous. A balloon charged with $\mathrm{CO}_{2}$ with a long needle was punched into the rubber septum and the tip of the needle submerged in the reaction mixture. The reaction was left to stir for 24 hours, and then quenched by adding $0.5 \mathrm{~mL}$ of water. The mixture was separated by flash column chromatography to yield benzyl glycerol carbonate (Benzyl GlyC) (4.79 g, 70\%). ${ }^{1} \mathrm{H}$ NMR (500 MHz, $\left.\mathrm{CDCl}_{3}\right): \delta$ 7.38-7.30 (m, 5H), 4.84-4.77 (m, 1H), 4.63-4.53 (m, 2H), 4.46 $(\mathrm{dd}, J=8.4,8.1 \mathrm{~Hz}, 1 \mathrm{H}), 4.36(\mathrm{dd}, J=8.4,8.4 \mathrm{~Hz}, 1 \mathrm{H}), 3.70(\mathrm{dd}, J=$ 11.1, 3.9 Hz, 1H), 3.60 (dd, $J=11.1,3.9 \mathrm{~Hz}, 1 \mathrm{H}) ;{ }^{13} \mathrm{C}$ NMR $(125$ $\left.\mathrm{MHz}, \mathrm{CDCl}_{3}\right): \delta 154.9,137.0,128.5,127.9,127.6,75.0,73.5,68.7$, 66.2; $\mathrm{m} / z$ : calcd for $\mathrm{C}_{11} \mathrm{H}_{12} \mathrm{O}_{4}: 208.0736$, [M] $]^{+}$; found: 208.0738 .

Ethyl glycerol carbonate (Ethyl GlyC) was synthesized using the same procedure but with the starting material ethylglycidyl ether. ${ }^{1} \mathrm{H}$ NMR $\left(500 \mathrm{MHz}, \mathrm{CDCl}_{3}\right): \delta 4.84-7.76(\mathrm{~m}, 1 \mathrm{H}), 4.49$ (dd, $J=8.4,8.1 \mathrm{~Hz}, 1 \mathrm{H}), 4.39(\mathrm{dd}, J=8.4,8.4 \mathrm{~Hz}, 1 \mathrm{H}), 3.69-3.57(\mathrm{~m}$, $2 \mathrm{H}), 3.50$ (q, $J=6.6 \mathrm{~Hz}, 2 \mathrm{H}), 0.91(\mathrm{dd}, J=7.5,7.2 \mathrm{~Hz}, 3 \mathrm{H}) ;{ }^{13} \mathrm{C}$ NMR (125 MHz, $\mathrm{CDCl}_{3}$ ): $\delta$ 154.9, 75.1, 71.1, 69.2, 65.8, 13.3; $\mathrm{m} / \mathrm{z}$ : calcd for $\mathrm{C}_{6} \mathrm{H}_{10} \mathrm{O}_{4}$ : 146.0579, [M] $]^{+}$; found: 146.0578.

Butyl glycerol carbonate (Butyl GlyC) was synthesized using the same procedure but with the starting material butyl glycidyl ether. ${ }^{1} \mathrm{H}$ NMR $\left(500 \mathrm{MHz}, \mathrm{CDCl}_{3}\right): \delta 4.84-7.76(\mathrm{~m}, 1 \mathrm{H}), 4.49$ (dd, $J=8.4,8.1 \mathrm{~Hz}, 1 \mathrm{H}), 4.39(\mathrm{dd}, J=8.4,8.4 \mathrm{~Hz}, 1 \mathrm{H}), 3.69-3.57$ (m, $2 \mathrm{H}), 3.50(\mathrm{t}, J=6.6 \mathrm{~Hz}, 2 \mathrm{H}), 1.65-1.50(\mathrm{~m}, 2 \mathrm{H}), 1.35(\mathrm{dt}, J=14.4$, $7.2 \mathrm{~Hz}, 2 \mathrm{H}), 0.91(\mathrm{dd}, J=7.5,7.2 \mathrm{~Hz}, 3 \mathrm{H}) ;{ }^{13} \mathrm{C}$ NMR $(125 \mathrm{MHz}$, $\left.\mathrm{CDCl}_{3}\right): \delta 154.9,75.1,71.1,69.2,65.8,31.0,18.6,13.3 ; \mathrm{m} / \mathrm{z}$ : calcd for $\mathrm{C}_{8} \mathrm{H}_{15} \mathrm{O}_{4}: 175.0970,[\mathrm{M}]^{+}$; found: 175.0968 .

\section{Characterization of glycerol carbonate electrolytes}

Thermal gravimetric analysis (TGA) was performed using a TGA Q50 while scanning from 20 to $500{ }^{\circ} \mathrm{C}$ at a heating rate of $20{ }^{\circ} \mathrm{C}$ $\mathrm{min}^{-1}$. Differential scanning calorimetry (DSC) was completed from $-70{ }^{\circ} \mathrm{C}$ to $100{ }^{\circ} \mathrm{C}$ at a heating rate of $10{ }^{\circ} \mathrm{C} \mathrm{min}{ }^{-1}$ and cooling rate of $5{ }^{\circ} \mathrm{C} \min ^{-1}$, the third trace was analyzed. Thermal degradation was defined as three percent weight lost. The conductivity measurements were carried out with a Conductivity Meter Probe (K912, Consort) under an argon atmosphere, to prevent trace amounts of moisture. A heating block was used to homogeneously heat the sample vial from room temperature up to $105{ }^{\circ} \mathrm{C}$. The samples were vacuum dried overnight before use. Viscosity was measured at $25{ }^{\circ} \mathrm{C}$ using an aluminum $2^{\circ}$ cone geometry (40 $\mathrm{mm}$ diameter) (TA Instruments AR2000 series). Prior to testing, samples were pre-sheared for $60 \mathrm{sec}$ at a shear rate of $2.5 \mathrm{~s}^{-1}$. A continuous flow shear rate sweep ( 1 to $100 \mathrm{~s}^{-1}$ ) was performed at temperatures ranging from $20-90{ }^{\circ} \mathrm{C}$ in ten degree increments and at $99.5{ }^{\circ} \mathrm{C}$. Data acquisition intervals were logarithmic, with five even logarithmically-spaced acquisition points per decade.

The electrochemical stability window was measured using a 3-electrode Split Test Cell (MTI Co.) by cyclic voltammetry at a scan rate of $20 \mathrm{mV} \mathrm{s}^{-1}$ and a potential window of -0.5 to $5.5 \mathrm{~V}$ at room temperature and $100{ }^{\circ} \mathrm{C}$. The cell was assembled in an argon-filled glove box using a $\mathrm{Li} / \mathrm{Li} / \mathrm{Pt}$ configuration.

\section{Supercapacitor measurements}

Activated carbon (AC: Sigma Aldrich-100 mesh particle size) was used as the active material for the electrodes. Working electrodes were made following the conventional procedure; grinding $75 \mathrm{wt} \%$ AC, $15 \mathrm{wt} \%$ acetylene black and $10 \mathrm{wt} \%$ poly(vinylidene fluoride) (PVDF) binder in $N$-methyl pyrrolidinone (NMP) solvent in a mortar. Prior to assembly, AC and acetylene black were dried at $80{ }^{\circ} \mathrm{C}$ and $120{ }^{\circ} \mathrm{C}$ in a vacuum oven, respectively. The resulting slurry was subsequently deposited onto already punched and washed titanium disks ( $\sim 1.58 \mathrm{~cm}$ in diameter). A typical electrode had a weight of active material of $2.5 \mathrm{mg}$ after drying under vacuum at $80{ }^{\circ} \mathrm{C}$ overnight. Electrochemical measurements were carried out on two identical electrodes (by weight and substrate) paired together to assemble a full device. Working electrodes were assembled into CR2032 coin cells (MTI Co.) separated by Celgard 480 membranes inside an argon-filled glove box. Lithium bis(trifluoro-methane-sulfonyl) imide (LiTFSI) was dissolved at 1.0 $\mathrm{M}$ in ethylene carbonate-dimethyl-carbonate (EC-DMC 1:1 vol \%), Benzyl GlyC, Ethyl GlyC, and Butyl GlyC and used as the electrolytes. Cyclic voltammetry (CV), charge-discharge (CD) and electrochemical impedance spectroscopy (EIS) measurements were performed using a Princeton Applied Research VersaStat battery tester. CV and CD tests were conducted over a voltage range of 0 to $2.5 \mathrm{~V}$ at various scan rates (from 1 to $1000 \mathrm{mV} \mathrm{s}^{-1}$ ) and different current densities (from 0.5 to $10 \mathrm{~A} \mathrm{~g}^{-1}$ ) at room temperature and $100{ }^{\circ} \mathrm{C}$. EIS measurements were conducted over a frequency range of $10 \mathrm{kHz}$ to $10 \mathrm{mHz}$ under a bias potential of $0.8 \mathrm{~V}$ using a $5 \mathrm{mV} \mathrm{rms}$ sinusoidal modulation. All calculations were based on the total weight of active materials.

\section{Results and discussion}

First, we measured the thermal stability of the novel glycerol carbonate using thermal gravimetric analysis (TGA) and all 
three glycerol carbonates are stable above $95{ }^{\circ} \mathrm{C}$ with thermal stability increasing with molecular weight; Benzyl GlyC exhibits the highest thermal stability to $190{ }^{\circ} \mathrm{C}$ while Ethyl GlyC displays the lowest thermal stability at $97{ }^{\circ} \mathrm{C}$. Moreover, differential scanning calorimetry (DSC) of the neat glycerol carbonates found no $T_{\mathrm{m}}$ or $T_{\mathrm{c}}$ for Ethyl or Butyl GlyC from -70 to $100{ }^{\circ} \mathrm{C}$, however, Benzyl GlyC did exhibit a $T_{\mathrm{m}}$ at $-54.6{ }^{\circ} \mathrm{C}$. We measured the viscosities of the glycerol carbonates at 25 and $100{ }^{\circ} \mathrm{C}$. At $25{ }^{\circ} \mathrm{C}$, Ethyl, Butyl, and Benzyl GlyC exhibit viscosities of 0.0094, 0.0096, and 0.076 Pa s, respectively. Butyl GlyC and Ethyl GlyC possess a similar viscosity value at $25{ }^{\circ} \mathrm{C}$, while Benzyl GlyC has a slightly higher value. The increased viscosity for Benzyl GlyC is likely a result of the larger molecular weight and pi-stacking interactions present. At $100{ }^{\circ} \mathrm{C}$ the viscosities of Ethyl, Butyl, and Benzyl GlyC are 0.0014, 0.0029, and 0.0062 Pa.s, respectively. The viscosities of all three GlyCs decrease at $100{ }^{\circ} \mathrm{C}$ with the change being greatest for Butyl GlyC and Ethyl GlyC. The increase in temperature further reduces the weaker intermolecular interactions present within the Butyl GlyCs and Ethyl GlyCs affording a greater decrease in viscosity compared to the Benzyl GlyC.

Next, we measured the ionic conductivity of the Ethyl, Butyl, and Benzyl GlyC solvents with 1.0 M LiTFSI as a function of temperature. As the temperature increases, the conductivity increases for all three electrolytes. Among the glycerol carbonate structures, the Butyl GlyC exhibits the highest ionic conductivity (0.45-3.76 mS cm ${ }^{-1}$ ) over the entire temperature range. At $25{ }^{\circ} \mathrm{C}$, the conductivity of Butyl GlyC with $1.0 \mathrm{M}$ LiTFSI is $0.5 \mathrm{mS} \mathrm{cm}^{-1}$ while Ethyl GlyC and Benzyl GlyC with 1.0 M LiTFSI exhibit similar values of less than $0.1 \mathrm{mS} \mathrm{cm}^{-1}$. At $110{ }^{\circ} \mathrm{C}$, the conductivity value for Butyl GlyC with 1.0 M LiTFSI is $\sim 4 \mathrm{mS} \mathrm{cm}^{-1}$, and is $4 \times$ greater compared to ambient temperature, while the Ethyl and Benzyl GlyCs with 1.0 M LiTFSI are 0.2 and $2 \mathrm{mS} \mathrm{cm}^{-1}$, respectively (Fig. 2a).

As Butyl GlyC with 1.0 M LiTFSI possesses the highest conductivity, we performed additional characterization studies on this electrolyte. Fig. 2b displays the electrochemical stability of Butyl GlyC containing 1.0 M LiTFSI, obtained via cyclic voltammetry (CV) using a 3-electrode split cell $\mathrm{Li} / \mathrm{Li} / \mathrm{Pt}$, as a function of temperature. No large redox reactions occur from -0.5 to $5.5 \mathrm{~V}$ at $25{ }^{\circ} \mathrm{C}$ and only a slight increase in the absolute current value is observed after 27 cycles, indicating the potential beginning of compound degradation. The effect is minimal. However, at $100{ }^{\circ} \mathrm{C}$, an oxidation peak appears at $4 \mathrm{~V}$ indicating oxidation of the electrolyte, and at $1.5 \mathrm{~V}$ and $0 \mathrm{~V}$ in the cathodic direction two large reduction reactions are observed. At $100{ }^{\circ} \mathrm{C}$, Butyl GlyC with 1.0 M LiTFSI exhibits a narrow electrochemical stability window. To further analyze the effects of high temperature on the electrolyte, we compared the $\mathrm{CV}$ curves obtained at $25{ }^{\circ} \mathrm{C}$ before and after heating at $100{ }^{\circ} \mathrm{C}$ (Fig. 2b). After heating and cycling at $100{ }^{\circ} \mathrm{C}$ and then cooling to room temperature, the electrolyte displays a similar electrochemical stability as the initial cycling. In order to extend the cycling life of the coin cells for future tests we chose a cut-off voltage of $2.5 \mathrm{~V}$ for further electrochemical analysis.

To explore the electrochemical stability of the glycerol carbonates, we prepared LIC coin cells with activated carbon-
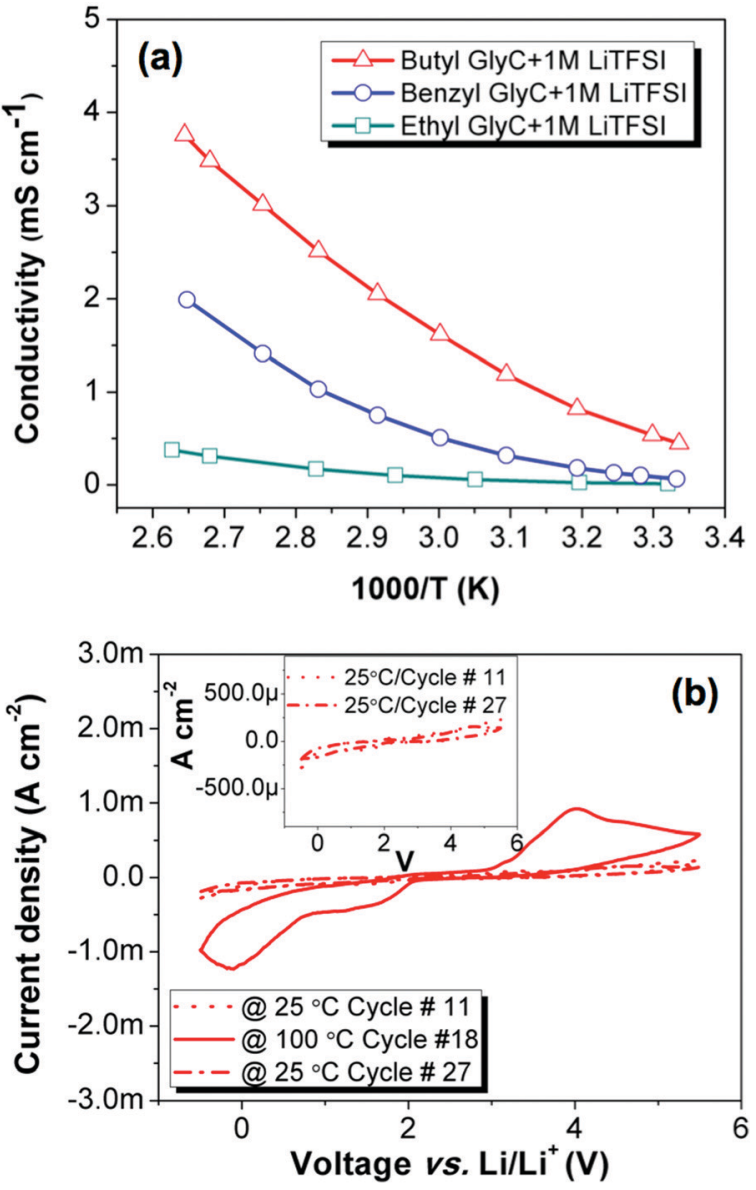

Fig. 2 (a) Ionic conductivity of Ethyl GlyC, Butyl GlyC, and Benzyl GlyC with $1.0 \mathrm{M}$ LiTFSI salt as a function of temperature. (b) Electrochemical stability window of Butyl GlyC electolyte at 25 and $100{ }^{\circ} \mathrm{C}$.

based electrodes and 1.0 M LiTFSI electrolyte solutions of Ethyl, Butyl, Benzyl GlyC and EC-DMC. CV curves of the cells at room temperature and scan rates of $20 \mathrm{mV} \mathrm{s}^{-1}$ and $1000 \mathrm{mV} \mathrm{s}^{-1}$ from 0 to $2.5 \mathrm{~V}$, respectively, are shown in Fig. $3 \mathrm{a}$ and b. At a scan rate of $20 \mathrm{mV} \mathrm{s}^{-1}$, all cells are electrochemically stable but only the EC-DMC and Butyl GlyC exhibit ideal capacitive behavior. At the accelerated scan rate of $1000 \mathrm{mV} \mathrm{s}^{-1}$, only the cell containing Butyl GlyC affords a CV curve showing capacitive behavior; illustrating the high rate capability of Butyl GlyC at room temperature (Fig. 3b). The CV curve obtained for Ethyl GlyC is not shown as it is comparable to Benzyl GlyC.

We performed additional electrochemical experiments at higher temperatures with cells only configured with the synthesized electrolytes due to thermal stability limits of EC-DMC beyond $80{ }^{\circ} \mathrm{C}$. The $\mathrm{CV}$ curve at $100{ }^{\circ} \mathrm{C}$ and a scan rate of $20 \mathrm{mV} \mathrm{s}{ }^{-1}$ from 0 to $2.5 \mathrm{~V}$, shows that Ethyl GlyC is not electrochemically stable with an oxidation reaction recorded at $0.75 \mathrm{~V}$ (Fig. 3c). The electrochemical instability of Ethyl GlyC at $100{ }^{\circ} \mathrm{C}$ originates at this slow scan rate primarily because the sample is heated at the onset of its thermal degradation temperature $\left(95^{\circ} \mathrm{C}\right)$. Butyl and Benzyl GlyC are thermally stable beyond this temperature, and, thus, no redox reactions are observed. At $1000 \mathrm{mV} \mathrm{s}^{-1}$, none of the glycerol carbonates display capacitive behavior, agreeing with our previous 

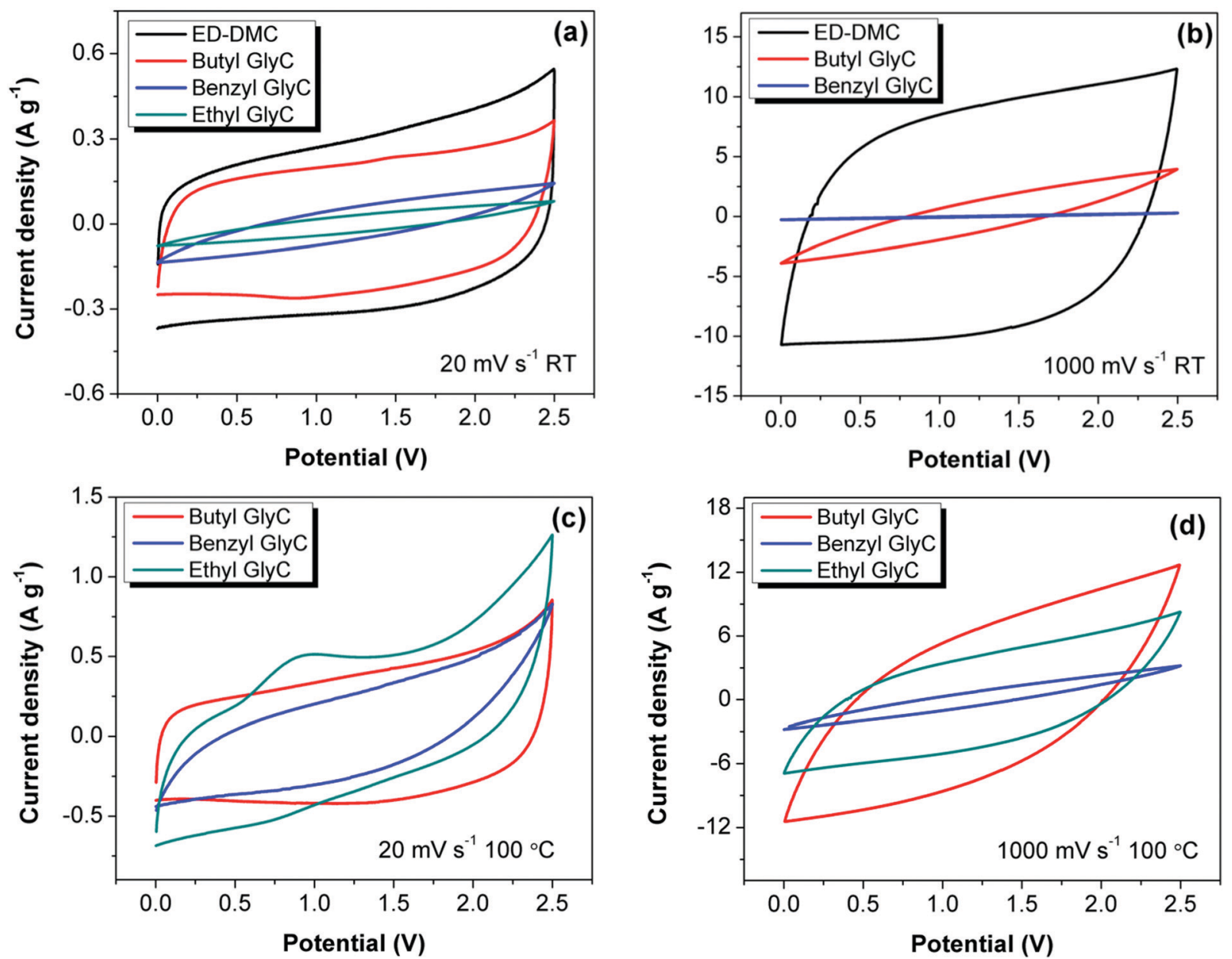

Fig. 3 Cyclic voltametric measurements: overlaid CV curves obtained for an AC supercapacitor cell, combined with different glycerol carbonate solvents and EC-DMC, as a control solvent, containing $1.0 \mathrm{M} \mathrm{LiTFSI} \mathrm{salt} \mathrm{at} \mathrm{room} \mathrm{temperature} \mathrm{with} \mathrm{a} \mathrm{scan} \mathrm{rate} \mathrm{of} \mathrm{(a)} 20 \mathrm{mV} \mathrm{s}^{-}$and (b) $1000 \mathrm{mV} \mathrm{s}$. Comparison of CV obtained for the synthesized electrolytes operated at high temperature with a scan rate of (c) $20 \mathrm{mV} \mathrm{s}^{-1}$ and (d) $1000 \mathrm{mV} \mathrm{s}^{-1}$.

work that $\mathrm{Li}$ ion intercalation is promoted in viscous electrolytes at higher temperatures and lower scan rates, establishing a pseudocapacitance charge contribution (Fig. 3d). ${ }^{5,14-17}$

We calculated the specific capacitance of each LIC to quantify the stability and performance of the glycerol carbonate electrolytes, by integrating the area under the CV curve using the following equation:

$$
C_{\mathrm{s}}=2 I /[(\mathrm{d} v / \mathrm{d} t) \times m]\left(\mathrm{F} \mathrm{g}^{-1}\right)
$$

where $C_{\mathrm{s}}$ is specific capacitance, $I$ is the charge-discharge current (A), $\mathrm{d} v / \mathrm{d} t$ is the scan rate $\left(\mathrm{V} \mathrm{s}^{-1}\right)$, and $m$ is the mass

Table 1 Capacitance values obtained from CV experiments conducted at different scan rates and temperatures

\begin{tabular}{llllllll}
\hline & \multicolumn{3}{c}{ Capacitance @ $\mathrm{RT}\left(\mathrm{F} \mathrm{g}^{-1}\right)$} & \multicolumn{3}{c}{ Capacitance @ 100} \\
\cline { 2 - 4 } & $\begin{array}{l}1 \\
\left(\mathrm{mV} \mathrm{s}^{-1}\right)\end{array}$ & $\begin{array}{l}20 \\
\left(\mathrm{mV} \mathrm{s}^{-1}\right)\end{array}$ & $\begin{array}{l}1000 \\
\left(\mathrm{mV} \mathrm{s}^{-1}\right)\end{array}$ & $\begin{array}{l}1 \\
\left(\mathrm{mV} \mathrm{s}^{-1}\right)\end{array}$ & $\begin{array}{l}20 \\
\left(\mathrm{mV} \mathrm{s}^{-1}\right)\end{array}$ & $\begin{array}{l}1000 \\
\left(\mathrm{mV} \mathrm{s}^{-1}\right)\end{array}$ \\
\hline Butyl GlyC & 29 & 21 & 4 & 115 & 38 & 14 \\
Benzyl GlyC & 28 & 7.4 & 0.3 & 96 & 30 & 3 \\
Ethyl GlyC & 15 & 4.2 & 0.3 & 162 & 45 & 9 \\
EC-DMC & 51 & 29 & 17 & - & - & -
\end{tabular}

(g) of the working electrode. ${ }^{18-20}$ We measured the performance of the LIC's at varying scan rates from $1 \mathrm{mV} \mathrm{s}^{-1}$ to $1000 \mathrm{mV} \mathrm{s}^{-1}$ and at room temperature and $100{ }^{\circ} \mathrm{C}$, and the results are summarized in Table 1 . At room temperature and $1 \mathrm{mV} \mathrm{s}^{-1}$, Butyl GlyC exhibits the highest specific capacitance, $29 \mathrm{~F} \mathrm{~g}^{-1}$, of all the glycerol carbonates. For all LIC cell configurations, a decline in capacitance occurs as the scan rate increases due to inherent ion diffusion limitations in the glycerol carbonate solvents. At $100{ }^{\circ} \mathrm{C}$, improved electrochemical performances are present at slow and fast scan rates. For instance, at room temperature and a scan rate of $1000 \mathrm{mV} \mathrm{s}^{-1}$, the Butyl GlyC exhibits a specific capacitance of $4 \mathrm{~F} \mathrm{~g}^{-1}$ but at $100{ }^{\circ} \mathrm{C}$ the specific capacitance increases $3 \times$ to $14 \mathrm{~F} \mathrm{~g} \mathrm{~g}^{-1}$. Interestingly, the LIC cell configured with Ethyl GlyC affords the highest specific capacitance value of $162 \mathrm{~F} \mathrm{~g}^{-1}$ at the scan rate of $1 \mathrm{mV} \mathrm{s}^{-1}$ at $100{ }^{\circ} \mathrm{C}$.

We next evaluated the LICs containing Butyl GlyC, Benzyl GlyC, Ethyl GlyC and EC-DMC with 1.0 M LiTFSI using galvanostatic charge-discharge (CD) cycling at room temperature and $100{ }^{\circ} \mathrm{C}$ with current densities of $0.5 \mathrm{~A} \mathrm{~g}^{-1}$ or $5 \mathrm{~A} \mathrm{~g}^{-1}$ (Fig. 4a-d). The CD curve obtained for Ethyl GlyC at ambient temperature is not shown as it is compared to Benzyl GlyC. 
The first five charge-discharge cycles of the LIC's with EC-DMC show the superior dynamic range of the standard carbonate electrolyte at $25{ }^{\circ} \mathrm{C}$ and $0.5 \mathrm{~A} \mathrm{~g}^{-1}$ current rate (Fig. 4a). At $100{ }^{\circ} \mathrm{C}$ and a current rate of $5 \mathrm{~A} \mathrm{~g}^{-1}$, the LIC with the Butyl GlyC electrolyte performs better than Benzyl GlyC and Ethyl GlyC with a long charge-discharge cycle (Fig. 4b). As the carbon chain length in the carbonate structure increases from ethyl to butyl, the LIC's capacitance improves.

The calculated specific capacitance and columbic efficiency $(\eta)$ for the different LIC's equipped with the three synthesized solvents and EC-DMC with 1.0 M LiTFSI operated at various current densities and temperatures are given in Table 2 . We calculated the specific capacitance of the LIC's from CD experiments using the following equation:

$$
C_{\mathrm{s}}=\frac{4 \times I_{\text {const }}}{m \times \frac{\mathrm{d} v}{\mathrm{~d} t}}
$$

where $I_{\text {const }}$ is the constant current applied, $\mathrm{d} v / \mathrm{d} t$ is the slope discharge curve, $\Delta V$ is the window potential $(\mathrm{V})$, and $\Delta t$ is discharge time $(\mathrm{s}) .^{21}$ At ambient temperate, the CD curves obtained for Butyl GlyC are comparable to EC-DMC, establishing that an EDLC is the dominant mechanism to store charge (Fig. 4a). At $100{ }^{\circ} \mathrm{C}$, galvanostatic cycling can be completed at an increased current density of $10 \mathrm{~A} \mathrm{~g}^{-1}$ and LIC's equipped with Butyl GlyC possess a specific capacitance and columbic efficiency of $13 \mathrm{~F} \mathrm{~g}^{-1}$ and $99 \%$, respectively (Table 2). As expected, elevated temperature enhances the ionic conductivity of the synthesized solvents, increasing the specific capacitance of the cell. While LIC cells equipped with Butyl GlyC produce high specific capacitance and coulombic efficiency, cells with Ethyl GlyC exhibit relatively high specific capacities but low columbic efficiencies (Table 2), and Benzyl GlyC equipped LICs cannot hold a charge and discharge within a second (Fig. 4b). Benzyl GlyC's inability to form a rate capable hybrid cell resulted in an overpotential CD curve at a current density of $10 \mathrm{~A} \mathrm{~g}^{-1}$ (see the ESI $\dagger$ ); this result shows that in cells with highly viscous solvents Li ion can become entrapped in the interplanar spaces of the AC electrodes, inhibiting the devices ability to completely discharge. ${ }^{22}$ Fig. 4c compares the CD curves obtained for Butyl
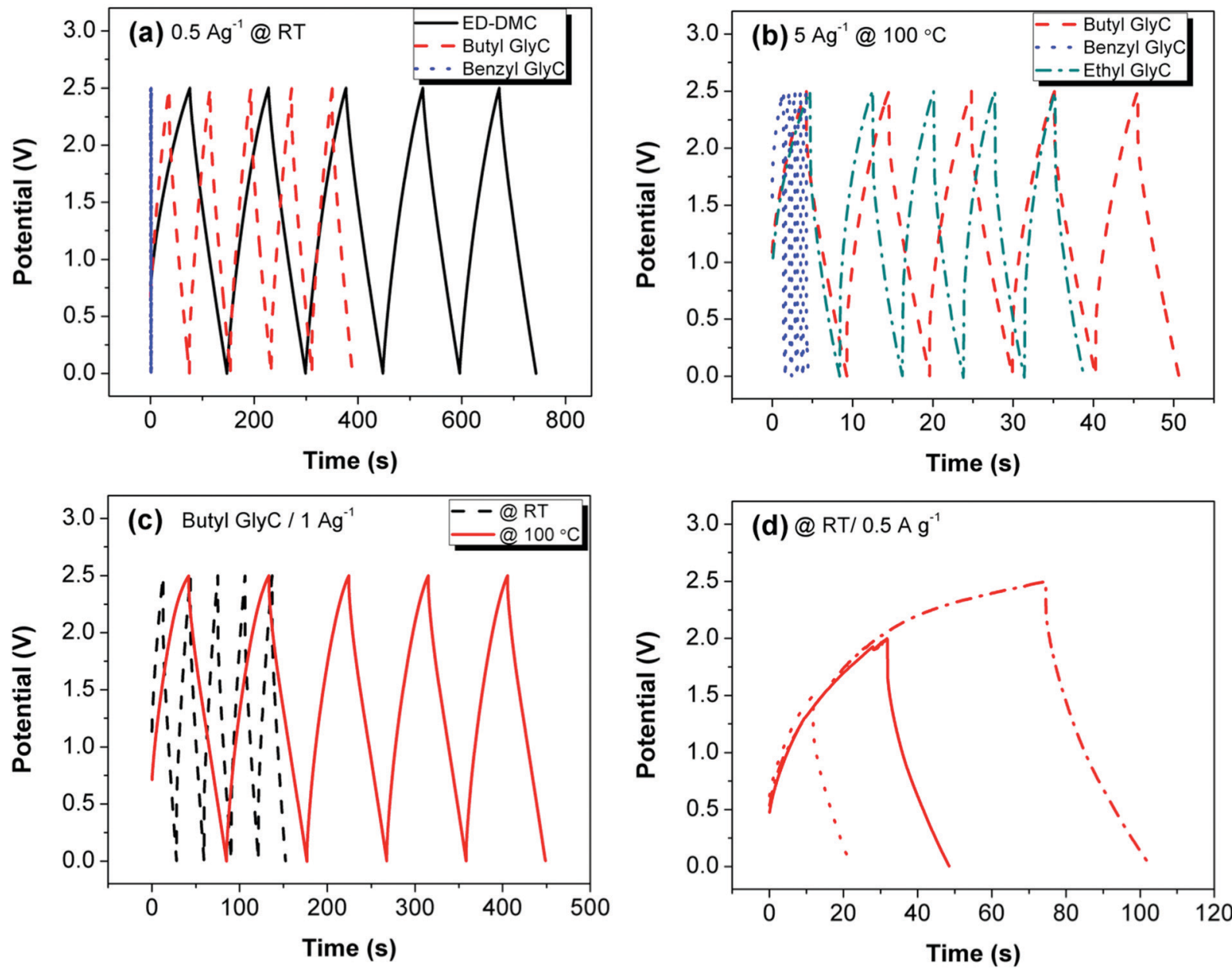

Fig. 4 Charge-discharge measurements: (a) Overlaid CD curves obtained in EC-DMC compared to the synthesized carbonate electrolytes at room temperature and a current density of $0.5 \mathrm{~A} \mathrm{~g}^{-1}$. (b) High temperature performance of Butyl, Benzyl, and Ethyl GlyC at a constant current density of $5 \mathrm{~A} \mathrm{~g}^{-1}$. (c) Comparable $\mathrm{CD}$ performance tested in butyl glycerol carbonate at $25^{\circ} \mathrm{C}$ and $100{ }^{\circ} \mathrm{C}$ at a current density of $5 \mathrm{~A} \mathrm{~g}^{-1}$. (d) $\mathrm{CD}$ responses at various applied voltages obtained from a coin cell configured with Butyl GlyC electrolyte after 800 cycling at $100{ }^{\circ} \mathrm{C}$. 
Table 2 Discharge capacitance and columbic efficiency calculated from CD tests at various current densities and operational temperatures

\begin{tabular}{|c|c|c|c|c|c|}
\hline & \multicolumn{2}{|c|}{$C^{a}\left(\mathrm{~F} \mathrm{~g}^{-1}\right)$ with $\eta^{b}(\%) @ \mathrm{RT}$} & \multicolumn{3}{|c|}{$C\left(\mathrm{~F} \mathrm{~g}^{-1}\right)$ with $\eta(\%) @ 100{ }^{\circ} \mathrm{C}$} \\
\hline Butyl GlyC & 15.5 with $97 \%$ & 12 with $98 \%$ & 34 with $90 \%$ & 20 with $97 \%$ & 13 with $99 \%$ \\
\hline Ethyl GlyC & - & - & 23 with $85 \%$ & 15 with $95 \%$ & 6.4 with $93 \%$ \\
\hline EC-DMC & 28 with $92 \%$ & 26 with $95 \%$ & - & - & - \\
\hline
\end{tabular}

GlyC at room temperature and $100{ }^{\circ} \mathrm{C}$ at a constant current density of $1 \mathrm{~A} \mathrm{~g}^{-1}$, at both temperatures there is a negligible IR drop at the start of the discharge curve indicating the formation of an efficient electric double layer capacitor with fast ion transport and low equivalent series resistance. Lastly, to highlight the wide operational potential window for the LIC equipped with the 1.0 M LiTFSI and Butyl GlyC electrolyte, we charged the cell at a fixed current rate of $0.5 \mathrm{~A} \mathrm{~g}^{-1}$ but increased the applied potential (Fig. 4d). As the potential region increased, the time to charge the cell increases indicating that a larger applied voltage enhances the capacitance of the cell.

To garner a deeper understanding of the internal resistance of the electrode and the electrolyte, we conducted an electrochemical impedance spectroscopy (EIS) experiment with a LIC cell configured with 1.0 M LiTFSI in Butyl GlyC. We equilibrated the LIC cell at 25,80 and $100{ }^{\circ} \mathrm{C}$ and obtained Nyquist and Bode plots of $\mathrm{AC} /$ Butyl $\mathrm{GlyC} / \mathrm{AC}$ at a constant potential of $0.8 \mathrm{~V}$ (illustrated in Fig. 5a and b). The Nyquist plot is linear from low to high frequencies, but in the high frequency region a slight semi-circle is present from 50 to $75 \mathrm{ohms}$ at $25{ }^{\circ} \mathrm{C}$ (Fig. 5a). At $80^{\circ} \mathrm{C}$ and $100{ }^{\circ} \mathrm{C}$ the plot is nearly a horizontal line relative to $Z^{\prime}$. Normally, a vertical line on the Nyquist plot at low frequencies and a $90^{\circ}$ phase angle on the Bode plot indicate a pure supercapacitor system, therefore, the slight semi-circle and deviation from the $90^{\circ}$ phase angle observed in the EIS measurement confirms the pseudocapacitive charge behavior of the Butyl GlyC electrolyte. Moving to intermediate and low frequencies, the data continue to form a linear line, indicating a diffusion mediated process at these frequencies. Thus, while the formation of an EDL is the main mechanism for energy generation, lithium ion intercalation into the electrode is present in the LICs. Additionally, as observed in the EIS experiments, charge transfer resistance reduces as the temperature of the experiment increases. This lower resistance is further corroborated by the increased capacitance at higher temperature. Together, the data demonstrate that the 1.0 M LiTFSI Butyl GlyC electrolyte exhibits low impedance and is easily able to transport the charge carriers, even at a high frequency. These findings are in line with the results observed in the $\mathrm{CV}$ and $\mathrm{CD}$ experiments.

The theoretical capacitance of the working electrode in a three-electrode configuration can be calculated from the EIS method using the following equation:

$$
C_{\mathrm{s}}=-1 /\left(2 \pi \mathrm{f} Z^{\prime \prime} m\right)
$$

where, $m$ is the mass of active material, $\mathrm{f}$ is the frequency and $Z^{\prime \prime}$ is the imaginary part of the impedance at low frequency. ${ }^{16}$
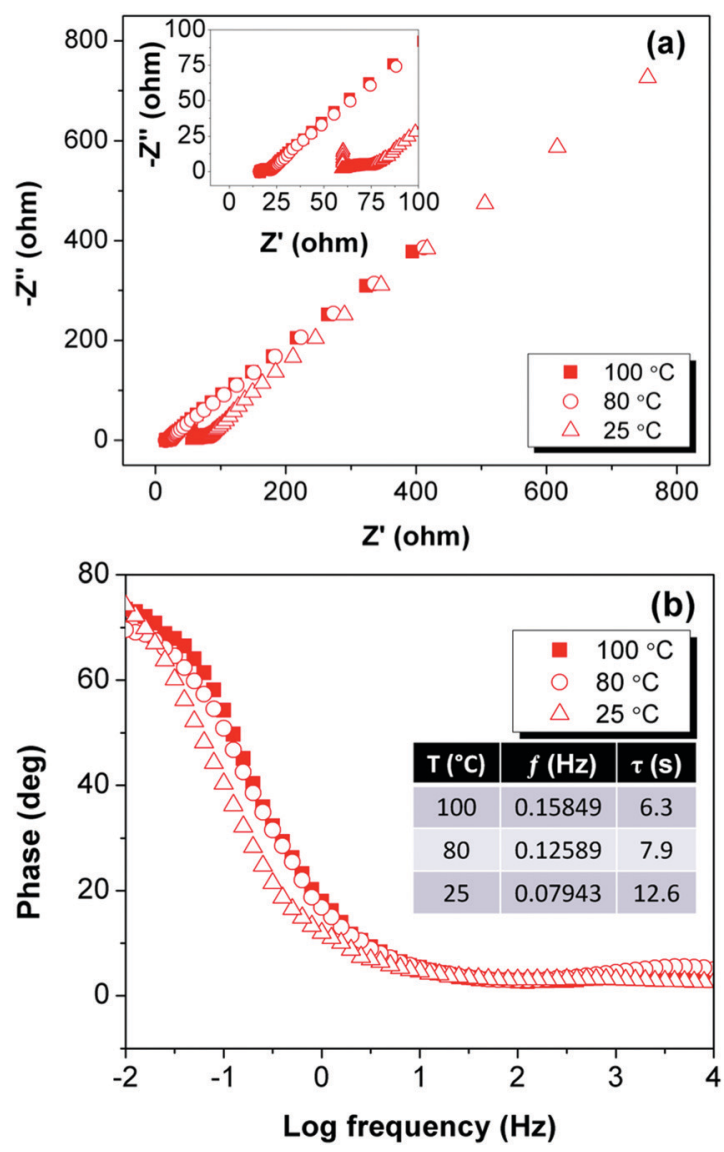

Fig. 5 Electrochemical Impedance spectroscopy: (a) Nyquist plots along with a high frequency region as the inset of $A C$ supercapacitors with $1.0 \mathrm{M}$ LiTFSI in Butyl GlyC. (b) Bode plots of an AC supercapacitor cell equipped with $1.0 \mathrm{M}$ LiTFSI in Butyl-GlyC obtained at different temperatures; the relaxation time constant of the device at different temperatures is estimated at a phase angle of $45^{\circ}\left(\tau_{0}=1 / f_{0}\right)$ and given as the inset.

Therefore, a lower $Z^{\prime \prime}$ results in a higher capacitance value. The cell operated at higher temperatures exhibits a much lower impedance value than at lower temperature emphasizing a higher capacitance in the low frequency region. As expected, in the high frequency region, and operating at ambient temperature results in higher solution resistance $(R=606 \Omega$; see inset in Fig. 5a) due to the lower ionic conductivity obtained at these conditions (Fig. 2a).

Next, we performed continuous galvanostatic chargedischarge cycling to evaluate the performance of the electrodes in contact with $1.0 \mathrm{M}$ LiTFSI in Butyl GlyC at $100{ }^{\circ} \mathrm{C}$. The 
specific discharge capacitance of the cells at applied current densities of 1 and $5 \mathrm{~A} \mathrm{~g}^{-1}$ are plotted in Fig. 6a. A steep decline in discharge capacitance occurs in the cell operated at lower current density while at a higher current density, the discharge capacitance remains steady up to the 1200th cycle. Higher applied current density affords a columbic efficiency of $96 \%$ at cycle 100 and $91 \%$ after the 1100th cycle (Fig. 6a). However, the columbic efficiency at the lower current density of $1 \mathrm{~A} \mathrm{~g}^{-1}$ was $90 \%$ at cycle 230 and significantly diminished to $62.5 \%$ at cycle 700 (data not shown). We attribute this behavior to the entrapment of $\mathrm{Li}$ ions in the interlayer of the $\mathrm{AC}$ electrode, which is promoted at higher temperatures and lower scan rates or current densities. ${ }^{22}$ Furthermore, the CD curve of the LIC cell with the Butyl GlyC electrolyte measured at $1 \mathrm{~A} \mathrm{~g}^{-1}$ and room temperature is comparable to the CD curve obtained after long term cycling at $100{ }^{\circ} \mathrm{C}$ (Fig. 6b). Continuous operation of the cell at elevated temperatures results in the shortening of the charge-discharge time and diminished capacitance of the cell.

We calculated the energy and power density of the LIC cells containing AC electrodes and the Butyl GlyC electrolyte following eqn (4) and (5) and the generated Ragone plot is illustrated in Fig. 7.

$$
E=1 / 8 C_{\mathrm{s}}(\Delta V)^{2}\left(\mathrm{~W} \mathrm{~h} \mathrm{~kg}^{-1}\right)
$$
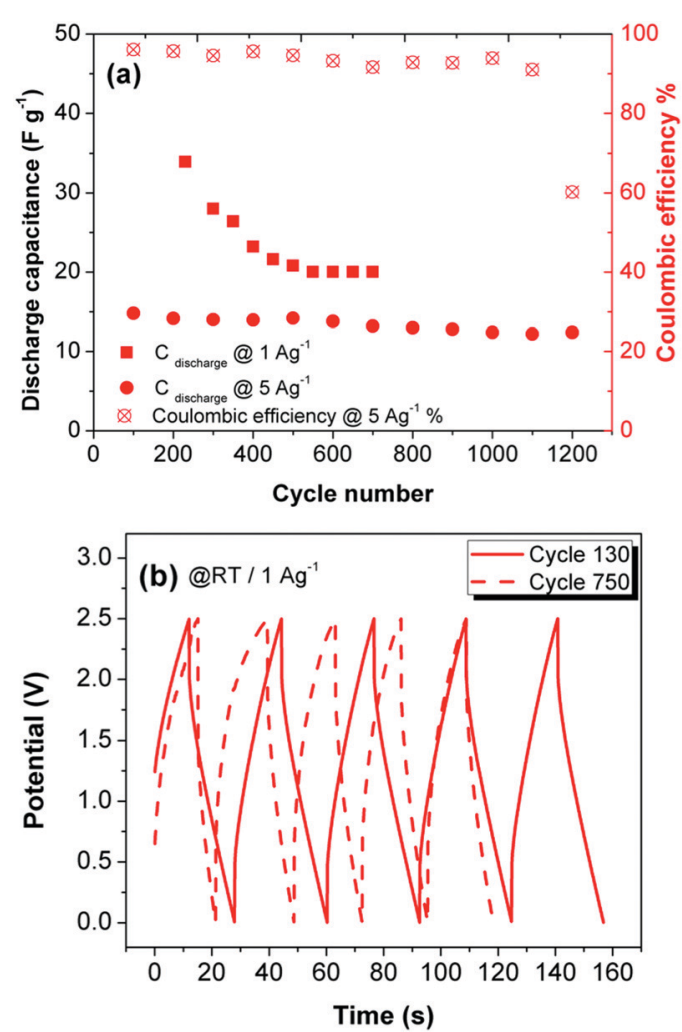

Fig. 6 Stability of the device: (a) long term cycling behavior of AC LIC cells combined with $1.0 \mathrm{M} \mathrm{LiTFSI}$ in Butyl GlyC at $100{ }^{\circ} \mathrm{C}$ and current densities of $1 \mathrm{~A} \mathrm{~g}^{-1}$ and $5 \mathrm{~A} \mathrm{~g}^{-1}$ over an applied potential of $2.5 \mathrm{~V}$. (b) Charge discharge profile at room temperature recorded before and after long term stability at $100{ }^{\circ} \mathrm{C}$.

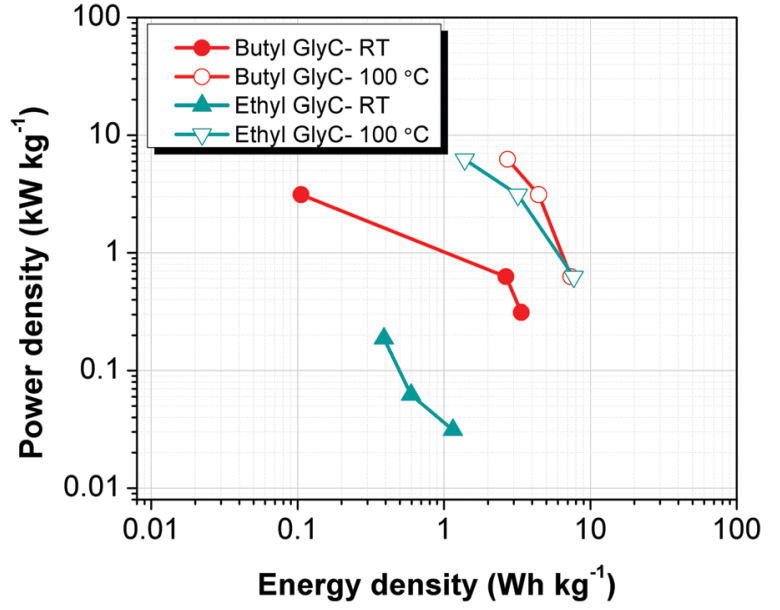

Fig. 7 Ragone plot for AC LIC cells configured with Ethyl GlyC and Butyl GlyC electrolytes and tested at room temperature (RT) and $100{ }^{\circ} \mathrm{C}$

$$
P=E / \Delta t\left(\mathrm{~W} \mathrm{~kg}^{-1}\right)
$$

where, $E$ is the energy density $\left(\mathrm{W} \mathrm{h} \mathrm{kg}^{-1}\right)$ and $P$ is the power density $\left(\mathrm{W} \mathrm{kg}^{-1}\right)$, and $\Delta V$ is the window potential (V). The LIC's containing the Butyl GlyC electrolyte affords an energy density and power density of $3.38 \mathrm{~W} \mathrm{~h} \mathrm{~kg}{ }^{-1}$ and $0.3 \mathrm{KW} \mathrm{kg}{ }^{-1}$ at an applied current of $0.5 \mathrm{~A} \mathrm{~g}^{-1}$ and room temperature and $2.7 \mathrm{~W} \mathrm{~h} \mathrm{~kg}^{-1}$ and $6.25 \mathrm{~kW} \mathrm{~kg}^{-1}$ at an applied current of $10 \mathrm{~A} \mathrm{~g}^{-1}$ and $100{ }^{\circ} \mathrm{C}$ (Fig. 7). Among the glycerol carbonates, Butyl GlyC provides the highest capacitance value at room temperature and overall better electrochemical qualities at both ambient temperature and $100{ }^{\circ} \mathrm{C}$.

In comparison with other studies utilizing $\mathrm{AC}$ as electrodes in supercapacitors, the glycerol carbonates performed with reduced discharge capacitance. For example, at ambient temperature a standard ACN electrolyte with $1.6 \mathrm{M} \mathrm{Et}_{4} \mathrm{NBF}_{4}$ (tetraethylammonium tetrafluoroborate), displayed a discharge capacitance of $26 \mathrm{~F} \mathrm{~g}^{-1} \cdot{ }^{23}$ And room temperature ionic liquid (RTILs) electrolytes evaluated at various temperatures displayed discharge capacitance $3-4 \times$ larger than our glycol carbonate based LICs. ${ }^{24-28}$ For instance, Balducci et al. used 1-butyl-1methylpyrrolidinium bis(trifluoro-methane-sulfonyl)imide in a microporous AC coin cell that exhibited a discharge capacitance of $90 \mathrm{~F} \mathrm{~g}^{-1}$ at $60{ }^{\circ} \mathrm{C}^{5}{ }^{5}$ While at first glance, RTIL systems seem to generate higher discharge capacitance compared to our system, on a deeper analysis it becomes clear that bare AC mixed with carbon black and a PVDF binder were not the only components used in the systems: more exotic and complex AC mixtures or electrodes have also been explored in high discharge systems. ${ }^{9,29}$ For example, $\mathrm{KOH}$-activated microwave exfoliated graphite oxide electrodes, ${ }^{30}$ D-glucose derived activated carbon powder, ${ }^{31}$ and lignin: PVA carbon fiber mats ${ }^{32}$ were used to develop systems with discharge capacitance of 130, 245 and $72 \mathrm{~F} \mathrm{~g}^{-1}$, respectively, at room temperature. Furthermore, mixtures of RTILs and traditional carbonate salts were combined to increase the discharge capacitance even while utilizing a simple AC electrode. ${ }^{33}$ For instance, tributyl-phosphine tetrafluoroborate was mixed with ACN, with a molar ratio of 0.86 , to generate a supercapacitor 
with a discharge capacitance of $120 \mathrm{~F} \mathrm{~g}^{-1}$ at $50{ }^{\circ} \mathrm{C}^{34}$ (see Table S1 in the $\mathrm{ESI} \dagger$ for a comprehensive list of all studies mentioned here). The above electrolyte systems have advantages, including high discharge capacitance, as well as weaknesses such as the need to include one or more of the following elements: complex electrodes, mixtures of flammable and toxic carbonate solvents, or the use of environmentally damaging reagents and work up processes. Given the stable electrochemical performance at ambient temperatures and $100{ }^{\circ} \mathrm{C}$, straightforward electrode fabrication, and overall environmentally benign synthesis and degradation, the glycerol carbonate system is a promising electrolyte system.

\section{Conclusions}

In summary, we describe the physicochemical and performance characteristics of three potential environmentally friendly glycerol carbonate solvents as electrolytes for lithium ion supercapacitors. The glycerol carbonates possess an ethyl, benzyl, or butyl pendant chain. The conductivity of the glycerol carbonate-based electrolytes with 1.0 M LiTFSI increases significantly with elevated temperatures, and all three electrolytes are electrochemically stable with a stability window of $2.5 \mathrm{~V} \mathrm{vs} \mathrm{Li} / \mathrm{Li}^{+}$. Lithium ion supercapacitors composed of activated carbon electrodes containing one of the glycerol carbonates or ECDMC with 1.0 M LiTFSI exhibit temperature and current rate dependent performances. At room temperature, the devices with the glycerol carbonate exhibit lower discharge capacitance compared to EC-DMC cells with capacitances of 15,28 , and $29 \mathrm{~F} \mathrm{~g}^{-1}$, at a current rate of $1 \mathrm{~A} \mathrm{~g}^{-1}$, for the ethyl, benzyl, and butyl glycerol carbonate electrolytes, respectively. However at $100{ }^{\circ} \mathrm{C}$ the EC-DMC supercapacitors no longer function. At $100{ }^{\circ} \mathrm{C}$, the supercapacitors containing the ethyl, benzyl, and butyl glycerol carbonate electrolytes perform well with discharge capacitances of 162,96 , and $115 \mathrm{~F} \mathrm{~g}^{-1}$ at a current rate of $1 \mathrm{~A} \mathrm{~g}^{-1}$, respectively. Lastly, supercapacitors containing Butyl GlyC exhibit long term stability with over $60 \%$ coulombic efficiency retention at a current of $5 \mathrm{~A} \mathrm{~g}^{-1}$ for over 1000 cycles at $100{ }^{\circ} \mathrm{C}$. These findings demonstrate the promising features of glycerol carbonate based solvent electrolytes, particularly at high temperatures. Continued development and evaluation of sustainable electrolytes for EES will further our knowledge on the design space for optimal electrolytes that address the requirements for supercapacitors and Li-ion batteries to operate at both room and elevated temperatures.

\section{Conflicts of interest}

The authors have no conflicts of interest.

\section{Acknowledgements}

This article was supported in part by Boston University and the NSF (DMR-1507081).

\section{References}

1 R. Lin, P.-L. Taberna, S. Fantini, V. Presser, C. R. Pérez, F. Malbosc, N. L. Rupesinghe, K. B. K. Teo, Y. Gogotsi and P. Simon, J. Phys. Chem. Lett., 2011, 2, 2396-2401.

2 M.-T. F. Rodrigues, X. Lin, H. Gullapalli, M. W. Grinstaff and P. M. Ajayan, J. Power Sources, 2016, 330, 84-91.

3 X. Lin, M. Salari, L. M. R. Arava, P. M. Ajayan and M. W. Grinstaff, Chem. Soc. Rev., 2016, 45, 5848-5887.

4 D. R. Wright, N. Garcia-Araez and J. R. Owen, Energy Procedia, 2018, 151, 174-181.

5 A. Balducci, R. Dugas, P. L. Taberna, P. Simon, D. Plee, M. Mastragostino and S. Passerini, J. Power Sources, 2007, 165, 922-927.

6 J. Chapman Varela, K. Sankar, A. Hino, X. Lin, W.-s. Chang, D. Coker and M. Grinstaff, Chem. Commun., 2018, 54, 5590-5593.

7 H. Li, L. Peng, D. Wu, J. Wu, Y.-J. Zhu and X. Hu, Adv. Energy Mater., 2019, 9, 1802930.

8 X. Wang, M. Salari, D.-e. Jiang, J. Chapman Varela, B. Anasori, D. J. Wesolowski, S. Dai, M. W. Grinstaff and Y. Gogotsi, Nat. Rev. Mater., 2020, 5, 787-808.

9 V. Ruiz, T. Huynh, S. R. Sivakkumar and A. G. Pandolfo, RSC Adv., 2012, 2, 5591-5598.

10 O. N. Kalugin, V. V. Chaban, V. V. Loskutov and O. V. Prezhdo, Nano Lett., 2008, 8, 2126-2130.

11 M. D. Stoller, S. Park, Y. Zhu, J. An and R. S. Ruoff, Nano Lett., 2008, 8, 3498-3502.

12 D. Yaakov, Y. Gofer, D. Aurbach and I. C. Halalay, J. Electrochem. Soc., 2010, 157, A1383-A1391.

13 Y. Lai, B. Peng, Z. Zhang and J. Li, J. Electrochem. Soc., 2014, 161, A875-A879.

14 M. Salari and M. W. Grinstaff, Meeting Abstracts, 2016, MA2016-02, 955-955.

15 C. Largeot, P. L. Taberna, Y. Gogotsi and P. Simon, Electrochem. Solid-State Lett., 2011, 14, A174-A176.

16 M. Salari, S. H. Aboutalebi, A. T. Chidembo, P. C. Innis, K. Konstantinov, H. K. Liu and P. Schmuki, Phys. Status Solidi A, 2014, 211, 938-945.

17 R. S. Borges, A. L. M. Reddy, M.-T. F. Rodrigues, H. Gullapalli, K. Balakrishnan, G. G. Silva and P. M. Ajayan, Sci. Rep., 2013, 3, 2572.

18 J. L. Goldfarb, G. Dou, M. Salari and M. W. Grinstaff, ACS Sustainable Chem. Eng., 2017, 5, 3046-3054.

19 M. F. El-Kady, V. Strong, S. Dubin and R. B. Kaner, Science, 2012, 335, 1326-1330.

20 J. Zhang, J. Jiang, H. Li and X. S. Zhao, Energy Environ. Sci., 2011, 4, 4009-4015.

21 Y. Zhu, S. Murali, M. D. Stoller, K. J. Ganesh, W. Cai, P. J. Ferreira, A. Pirkle, R. M. Wallace, K. A. Cychosz, M. Thommes, D. Su, E. A. Stach and R. S. Ruoff, Science, 2011, 332, 1537-1541.

22 M. Salari, B. G. Cooper, H. Zhang and M. W. Grinstaff, Adv. Sustainable Syst., 2017, 1, 1700067.

23 X. Bu, L. Su, Q. Dou, S. Lei and X. Yan, J. Mater. Chem. A, 2019, 7, 7541-7547.

24 L. Zhang, K. Tsay, C. Bock and J. Zhang, J. Power Sources, 2016, 324, 615-624. 
25 R. Thangavel, A. G. Kannan, R. Ponraj, V. Thangavel, D.-W. Kim and Y.-S. Lee, J. Power Sources, 2018, 383, 102-109.

26 L. Timperman, F. Beguin, E. Frackowiak and M. Anouti, J. Electrochem. Soc., 2014, 161, A228-A238.

27 K. L. Van Aken, M. Beidaghi and Y. Gogotsi, Angew. Chem., Int. Ed., 2015, 54, 4806-4809.

28 K. K. Denshchikov, M. Y. Izmaylova, A. Z. Zhuk, Y. S. Vygodskii, V. T. Novikov and A. F. Gerasimov, Electrochim. Acta, 2010, 55, 7506-7510.

29 R. Zarrougui, R. Hachicha, R. Rjab and O. Ghodbane, J. Mol. Liq., 2018, 249, 795-804.
30 W.-Y. Tsai, R. Lin, S. Murali, L. L. Zhang, J. K. McDonough, R. S. Ruoff, P.-L. Taberna, Y. Gogotsi and P. Simon, Nano Energy, 2013, 2, 403-411.

31 T. Tooming, T. Thomberg, L. Siinor, K. Tonurist, A. Janes and E. Lust, J. Electrochem. Soc., 2014, 161, A222-A227.

32 R. A. Perera Jayawickramage and J. P. Ferraris, Nanotechnology, 2019, 30, 155402.

33 J. Guo, M. Ye, K. Zhao, J. Cui, B. Yang, J. Meng and X. Yan, Colloids Surf., A, 2020, 598, 124858.

34 L. Timperman, H. Galiano, D. Lemordant and M. Anouti, Electrochem. Commun., 2011, 13, 1112-1115. 